\title{
Effect of Semisolid Formulation of Persea Americana Mill (Avocado) Oil on Wound Healing in Rats
}

\author{
Ana Paula de Oliveira, ${ }^{1}$ Eryvelton de Souza Franco, ${ }^{2}$ \\ Rafaella Rodrigues Barreto, ${ }^{2}$ Daniele Pires Cordeiro, ${ }^{2}$ Rebeca Gonçalves de Melo, ${ }^{2}$ \\ Camila Maria Ferreira de Aquino, ${ }^{2}$ Antonio Alfredo Rodrigues e Silva, ${ }^{2}$ \\ Paloma Lys de Medeiros, ${ }^{3}$ Teresinha Gonçalves da Silva, ${ }^{4}$ \\ Alexandre José da Silva Góes, ${ }^{4}$ and Maria Bernadete de Sousa Maia ${ }^{2,5}$ \\ ${ }^{1}$ Department of Pathology, Federal University of Pernambuco, 50670-901 Recife, PE, Brazil \\ ${ }^{2}$ Department of Physiology and Pharmacology, Federal University of Pernambuco, 50670-901 Recife, PE, Brazil \\ ${ }^{3}$ Department of Histology and Embryology, Federal University of Pernambuco, 50670-901 Recife, PE, Brazil \\ ${ }^{4}$ Department of Antibiotics, Federal University of Pernambuco, 50670-901 Recife, PE, Brazil \\ ${ }^{5}$ Department of Physiology and Pharmacology, Laboratory of Pharmacology of Bioactive Products, Federal University of Pernambuco, \\ 50670-901 Recife, PE, Brazil
}

Correspondence should be addressed to Maria Bernadete de Sousa Maia; mbsm@ufpe.br

Received 22 January 2013; Accepted 13 February 2013

Academic Editor: Gerhard Litscher

Copyright (C) 2013 Ana Paula de Oliveira et al. This is an open access article distributed under the Creative Commons Attribution License, which permits unrestricted use, distribution, and reproduction in any medium, provided the original work is properly cited.

\begin{abstract}
The aim of this study was to evaluate the wound-healing activity of a semisolid formulation of avocado oil, SSFAO 50\%, or avocado oil in natura, on incisional and excisional cutaneous wound models in Wistar rats. An additional objective was to quantify the fatty acids present in avocado oil. On the 14th day, a significant increase was observed in percentage wound contraction and reepithelialization in the groups treated with $50 \%$ SSFAO or avocado oil compared to the petroleum jelly control. Anti-inflammatory activity, increase in density of collagen, and tensile strength were observed inSSFAO $50 \%$ or avocado oil groups, when compared to control groups. The analysis of the components of avocado oil by gas chromatography detected the majority presence of oleic fatty acid (47.20\%), followed by palmitic (23.66\%), linoleic (13.46\%) docosadienoic (8.88\%), palmitoleic (3.58\%), linolenic (1.60\%), eicosenoic (1.29\%), and myristic acids (0.33\%). Our results show that avocado oil is a rich source of oleic acid and contains essential fatty acids. When used in natura or in pharmaceutical formulations for topical use, avocado oil can promote increased collagen synthesis and decreased numbers of inflammatory cells during the wound-healing process and may thus be considered a new option for treating skin wounds.
\end{abstract}

\section{Introduction}

Wound healing is a complex process involving different cell types, cytokines, growth factors, and the extracellular matrix with the purpose of swiftly reestablishing skin integrity [13]. This wound healing process occurs in three overlapping phases: inflammation, proliferation, and remodeling [4-11].

Hemostasis is followed after several hours by an inflammatory stage, during which cytokines and growth factors are secreted, and leucocytes and to a lesser extent other cell types are recruited to clean the wound. In the proliferative phase tissue repair occurs in response to the factors produced initially. Endothelial cells proliferate to form new blood vessels that are essential for supplying blood to the wound site. A proliferation of fibroblasts also occurs, thus establishing a proper wound bed for reepithelialization, which starts with the proliferation and centripetal migration of keratinocyte from the wound edges or from hair follicles and sweat glands in the remaining dermis. During the last phase, the following events occur: regression of capillaries, reorganization of the extracellular matrix, and restructuring of scar tissue, which may take many months if not years [12-14]. 
Previous studies have shown that the healing process may be modulated by fatty acids $[8,10]$. Linolenic $(18: 3 \omega-3)$, linoleic $(18: 2 \omega-6)$, and oleic $(18: 1 \omega-9)$ acids are precursors of eicosapentaenoic (EPA) (20:5 $\omega$-3), arachidonic (AA) (20:4 $4-6)$, and eicosatrienoic acids (ETA) $(20: 3 \omega-9)$ which are part of the structure of cell membrane phospholipids and serve as substrates for the synthesis of eicosanoids (inflammatory mediators), such as prostaglandins, thromboxanes, prostacyclins (via cyclooxygenase), and leukotrienes (via lipooxygenase) [15-20]. Eicosanoids formed from arachidonic acid, prostaglandin E2, thromboxane B2, and leukotriene B4 are proinflammatory inducers, more potent than those formed from EPA, prostaglandin E3, thromboxane B3, and leukotriene B5, which have anti-inflammatory effects $[15,18,19,21]$. Considering that these families of fatty acids compete for the same enzyme, the proper balance between $\omega 3, \omega 6$, and $\omega 9$ is of great importance [18]. Depending on the $\omega 3: \omega 6: \omega 9$ ratio of the diet more proinflammatory or anti-inflammatory eicosanoids can be synthesized. Besides modulating the inflammatory response, eicosanoids also act in immunological responses, platelet aggregation, and cell growth and differentiation [22].

Avocado ( $P$. americana) extract or oil in natura has been used in wound healing $[23,24]$, the treatment of psoriasis [25], wrinkles, and stretch marks [26, 27], as well as for their hepatoprotective actions [28]. The unsaponifiable fraction of this oil has regenerative properties of the epidermis [26, 27], besides improving scleroderma [29].

Avocado oil extracted from the pulp of the fruit is rich in polyunsaturated fatty acids (PUFAs), linoleic (6.1-22.9\%) and linolenic acids (0.4-4.0\%), and the monounsaturated fatty acid (MUFA), oleic acid (31.8-69.6\%). It also contains $\beta$-sitosterol, $\beta$-carotene, lecithin, minerals, and vitamins $\mathrm{A}$, $\mathrm{C}, \mathrm{D}$, and $\mathrm{E}[23,30-34]$. Therefore, the aim of this study was to evaluate the wound-healing activity of a semisolid formulation of avocado oil, SSFAO $50 \%$, or avocado oil in natura on incisional and excisional cutaneous wound models in Wistar rats and to characterize the fatty acids present in avocado oil.

\section{Materials and Methods}

2.1. Extraction and Fatty Acid Characterization of the In Natura Avocado Oil. The in natura oil of avocado (fruit), Margarida variety, was extracted using hexane as extraction solvent, following the method described by Salgado et al. [33]. The phytochemical characterization of the oil in natura in terms of its composition of fatty acids was determined after converting them into methyl esters [35]. The sample was analyzed using a Thermo Trace Ultra GC (SHIMADZU, model GC-14B) apparatus equipped with a flame ionization detector and HP-20 (carbowax $20 \mathrm{~m}$ ) capillary column $(25 \mathrm{~m}$ $\times 0.32 \mathrm{~mm} \times 0.3 \mu \mathrm{m})$. The column temperature was initially set to $40^{\circ} \mathrm{C}$ for $1 \mathrm{~min}$, then increased to $150^{\circ} \mathrm{C}$ at heating to $55^{\circ} \mathrm{C} / \mathrm{min}$, and finally increased to $220^{\circ} \mathrm{C}$ at $1.7^{\circ} \mathrm{C} / \mathrm{min}$. The injector and detector temperatures were 200 and $220^{\circ} \mathrm{C}$, respectively. Nitrogen was used as the carrier gas at a flow rate of $1.0 \mathrm{~mL} / \mathrm{min}$; injection was in split mode $(1: 20)$, and the injection volume was $1.0 \mu \mathrm{L}$ of the test sample. A standard fatty acid methyl ester mixture (Supelco, USA) was used to identify fatty acid methyl esters by their retention time. Fatty acid data were expressed as percent of total peak area.

2.2. Pharmaceutical Formulation. The semisolid formulation of avocado oil, SSFAO 50\%, was composed of avocado oil and a vehicle (petroleum jelly), in sufficient amount to daily treatment, order of ensures formulation stability. This manipulation met the standards and quality control for medicines from the Synthesis of Substances of Therapeutic Interest Laboratory, Department of Antibiotics of the Federal University of Pernambuco. As a negative control, the formulation vehicle (petroleum jelly) was used, and as a positive control, an oil rich in essential fatty acids (EFA) (Curatec EFA). The preclinical toxicity tests conducted in our laboratory to evaluate the dermal and ocular irritation, sensitization, and toxicity (acute and subchronic) of an SSFAO or in natura avocado oil in rodents and lagomorphs did not show any clinical signs of toxicity.

2.3. Animals. A total of 64 adult Wistar rats, male and female, with ages between 3-4 months and weighing between 200-250 g, were used. The animals came from the vivarium of the Department of Physiology and Pharmacology of the Federal University of Pernambuco. The rats were kept individually in metabolic cages, in $12 \mathrm{~h}$ light/dark cycle and at a constant temperature $\left(20 \pm 2^{\circ} \mathrm{C}\right)$, with water and food ad libitum, throughout the experiment. The experiments were approved by the Ethics Committee for Animal Experimentation (number 23076.027831/2010-21) of the Federal University of Pernambuco, Recife, Brazil.

2.4. Excisional Wound Model and Treatments. The excisional wound model (secondary intention) is adequate for biochemical and histological assessment of healing [36]. The cutaneous wound model was performed as described previously $[37,38]$. Twenty-four Wistar rats, male and female, were intramuscularly anesthetized with xylazine $\left(3 \mathrm{mg} \mathrm{kg}^{-1}\right)$ and ketamine (10 $\mathrm{mg} \mathrm{kg}^{-1}$ i.m.) [39], followed by manual trichotomy and antisepsis with $0.1 \%$ iodine alcohol at the dorsal midline of the cervical region. A circular area of approximately $78.5 \mathrm{~mm}^{2}$ of skin (subcutaneous tissue and fascia) was surgically removed using straight iris scissors and Adson forceps. A containment ring made of nontoxic and hypoallergenic silicone was sutured into place, with six stitches arranged symmetrically using 4.0-nylon monofilament, so that the surgical wound would remain in the center [38].

Injured rats were randomly divided into four groups ( $n=6)$, with each group receiving a different treatment. The wound was treated with topical application $( \pm 100 \mathrm{mg})$ of $50 \%$ SSFAO, in natura avocado oil, EFA (positive control), or petroleum jelly (negative control), once daily for 14 consecutive days.

2.5. Macroscopic Analysis. Area of wounds at each time point was determined by the formula: $A=\pi \cdot R \cdot r$, where " $A$ " represents the area $\left(\mathrm{mm}^{2}\right)$, " $R$ " larger radius, and " $r$ " smaller radius [38]. Thus, percentage wound contraction at each time point was derived by the following formula: percent 
wound contraction $=($ initial wound area - current area $) /$ initial wound area $\times 100 \%$ [40]. Measurements were made daily by the same examiner using a digital caliper, with the animals under physical restraint. The crusts of the wounds were removed on the seventh day to allow the evaluation of the accurate value of the remaining wound area and the tissue that was below them. The presence of granulation tissue, exudate and fibrin (slough), and crust formation as well as reepithelialization were also evaluated.

2.6. Histopathological and Histomorphometric Analysis. At 15 days after operation, animals were euthanized in a $\mathrm{CO}_{2}$ chamber to allow the collection of treated sites for the histopathological and histomorphometric analysis. The samples was fixed in $10 \%$ buffered formalin for 24 hours, and subsequently dehydrated in ethanol, cleared in xylene, embedded in paraffin wax, and sliced with a cryotome (Minot-type). Tissue sections (thickness $4 \mu \mathrm{m}$ ) were placed on slides previously coated with Mayer's albumin and after drying were stained with hematoxylin and eosin for morphological assessment $[41,42]$ and with Masson's Trichrome to collagen analysis [42, 43]. The slides were examined with a light microscope combined with a digital camera (Olympus BX-49); five images per field $\left(0.0018 \mathrm{~mm}^{2}\right)$ were captured (total magnification $400 \mathrm{x}$ ) to obtain the mean. The images (pixel resolution $480 \times 752$ ) were stored and subjected to counting of inflammatory cells, fibroblast cells, number of blood vessels, and collagen density with the aid of ImageJ software (National Institutes of Health, USA). In the RGB system (red-green-blue), the values for blue were used for determinate collagen density, where the blue area was mathematically divided by the RGB area and multiplied by $100 \%$.

2.7. Incisional Wound Model and Treatments. The incisional wound model (first intention) is excellent for biomechanical analysis of wound strength [36]. Forty Wistar rats, male and female, were intramuscularly anesthetized with xylazine (3 $\mathrm{mg} \mathrm{kg}^{-1}$ ) and ketamine (10 $\mathrm{mg} \mathrm{kg}^{-1}$ i.m.) [39], followed by manual trichotomy and antisepsis with $0.1 \%$ iodine alcohol in the region of the dorsal midline. Afterwards, incisional wounds $3 \mathrm{~cm}$ in length were made in the skin using a number 15 scalpel. The site was dissected with blunt dissection to offset the adjacent muscle-aponeurotic plane, then repositioned, and sutured with two simple stitches using 4.0-nylon monofilament. After the operation, the rats were randomly divided into four groups $(n=10)$ and treated with topical application ( $\pm 100 \mathrm{mg}$ ) of $50 \%$ SSFAO, in natura avocado oil, EFA (control positive), or petroleum jelly (negative control), once daily for 10 consecutive days. The sutures were removed on the eighth day. On the 11th day after operation, the animals were euthanized in a $\mathrm{CO}_{2}$ chamber and a $3 \times 6 \mathrm{~cm}$ fragment of skin around the wound site was removed. The tensile strength of the fragments was analyzed by an EMIC tensiometer, model DL-500 MF, maximum capacity $5 \mathrm{kN}$. Forces were applied, perpendicular to the scar at a speed of $5 \mathrm{~mm} / \mathrm{min}$. The maximum strength was considered to be the greatest force or charge applied to the fragment until it ruptured.
2.8. Statistical Analysis. Results were expressed as means \pm SEM and subjected to one-way ANOVA (inflammatory cells, fibroblast cells, number of blood vessels, collagen density, percent contraction wound, and tensile strength of the skin) or two-way ANOVA (presence of crust, exudate, fibrin-slough, and tissue reepithelialization) with Bonferroni's posttest comparing the treatment groups with SSFAO $50 \%$ or in natura avocado oil to the EFA and petroleum jelly controls, considering values of $P<0.05$ statistically significant. All statistical analyses were performed using Graph Pad Prism Instant, version 5.0 (GraphPad Software, San Diego, CA/USA).

\section{Results}

3.1. Fatty Acid Characterization in the Avocado Oil in Natura. The fatty acid (FA) methyl esters were identified using GC, and the relative content of each component was determined by the peak area normalization method. The following ratio was observed: $24.00 \%$ saturated fatty acid (SFA), $52.06 \%$ monounsaturated fatty acid (MUFA), and $23.94 \%$ polyunsaturated fatty acid (PUFA). This study indicated that avocado oil has a high content $(47.20 \%)$ of oleic acid $(\mathrm{C} 18: \ln 9 \mathrm{c})$, followed by $(23.66 \%)$ palmitic acid (C16:0), (13.46\%) linoleic acid (C18:2n6c), (8.88\%) cis-13, 16-docosadienoic acid (C22:2), (3.58\%) palmitoleic acid (C16:1), (1.60\%) linolenic acid (C18:3n3), (1.29\%) cis-11-eicosenoic acid (C20:1), and (0.33\%) myristic acid (C14:0).

3.2. Development of Excisional Wounds. To evaluate whether the treatment with SSFAO $50 \%$ or in natura avocado oil influenced the time for excisional wound closure, daily measurements were taken of all animals. On the fifth day of treatment, a significant difference $(P<0.05)$ was observed in percentage wound contraction in groups treated with $50 \%$ SSFAO $(6.92 \pm 2.55 \%)$ and in natura avocado oil $(0.00 \pm 0.00 \%)$ when compared to the EFA control (13.52 $\pm 1.25 \%)$. However, on the 13th day, there was a significant improvement in percentage wound contraction in the 50\% SSFAO treated group $(100.00 \pm 0.00 \%)$ when compared to the petroleum jelly control $(94.14 \pm 2.81 \%)$. On the 14 th day there was a significant increase percentage wound contraction in the groups 50\% SSFAO (100.00 $\pm 0.00 \%)$ and in natura avocado oil $(99.52 \pm 0.48 \%)$ when compared to petroleum jelly control $(91.63 \pm 3.35 \%$, \% wound contraction of day 0$)$ (Figure 1$)$. A significant increase $(P<0.05)$ in the presence of crust was observed on the second day treatment, in the group treated with SSFAO $50 \%$ or in natura avocado oil (six animals$100 \%)$ compared to the EFA control group (0\%).

After removal of the crust (seventh day), a significant decrease $(P<0.05)$ was observed in the presence of fibrin (slough) in the groups treated with SSFAO $50 \%$ or in natura avocado oil ( $0 \%)$ compared to the petroleum jelly control (two animals-33.33\%). The presence of serous exudate was observed in the early postoperation hours in all animals. A significant decrease $(P<0.05)$ in the presence of exudate was seen in the seventh day in the group treated with in natura avocado oil (four animals-66.66\%) compared to the petroleum jelly control (six animals-100\%). At the other 


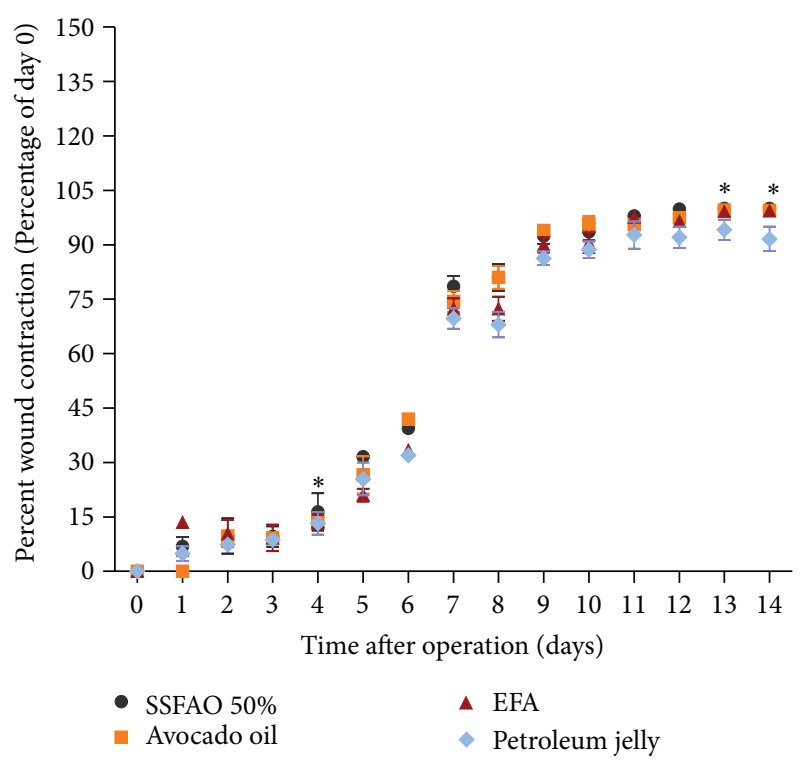

Figure 1: Percentage of wound contraction during the experimental period of treatment groups with SSFAO 50\%, in natura avocado oil, EFA (control positive), or petroleum jelly (control negative). On the fifth day, SSFAO $50 \%$ or avocado oil groups maintained the percentage of contraction of wound slower, when compared to the EFA control. However, on the 14th day, there was a significant improvement in percentage wound contraction in the SSFAO 50\% or in natura avocado oil groups when compared to the petroleum jelly control. Data are shown as average $\pm \operatorname{SEM}(n=06) .{ }^{*} P<0.05$ versus controls, ${ }^{* *} P<0.01$ versus controls, and ${ }^{* * *} P<0.001$ versus controls.

time periods, there was no significant difference these variables when comparing the treatment groups to the controls.

3.3. Histomorphometric Analysis of Excisional Wounds. To determine the effect of SSFAO $50 \%$ or in natura avocado oil on tissue repair of excisional wounds, histopathological and histomorphometric analyses were performed on all animals (number of fibroblast and inflammatory cells, number of blood vessels, collagen density, and reepithelialization) of the dermal region treated for 14 days. A significant increase was observed in reepithelialization in the groups treated with $50 \%$ SSFAO or in natura avocado oil (six animals-100\%) compared to the petroleum jelly control (three animals50\%) (Figure 2).

Histopathological and histomorphometric analyses showed anti-inflammatory action in groups treated with SSFAO $50 \%$ or in natura avocado oil $(2.50 \pm 0.15$ cells, $2.71 \pm 0.12$ cells, resp.) when compared with the EFA control (10.00 \pm 0.41 cells $)$ or petroleum jelly control $(28.82 \pm 1.70$ cells, resp. (Figures 3(a) and 3(b)). A significant decrease $(P<0.05)$ was observed in the number of fibroblast cells in the group treated with $50 \%$ SSFAO $(20.56 \pm 1.80$ cells $)$ when compared with the EFA control ( $36.45 \pm 1.68$ cells) or petroleum jelly control $(29.37 \pm 0.88$ cells $)$, respectively. Also observed a significant decrease in the fibroblast cells in the group treated with in natura avocado oil ( $26.30 \pm 0.73$ cells) when compared with EFA control (36.45 \pm 1.68 cells) (Figures 3(a) and 3(c)).
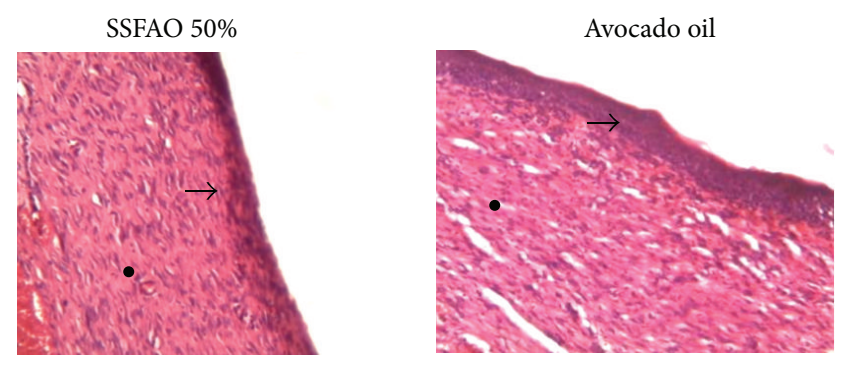

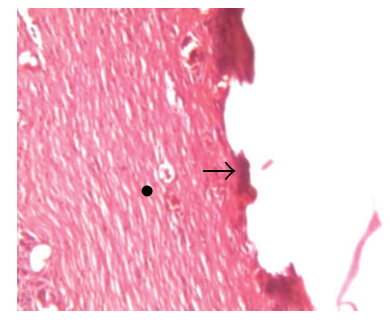

EFA

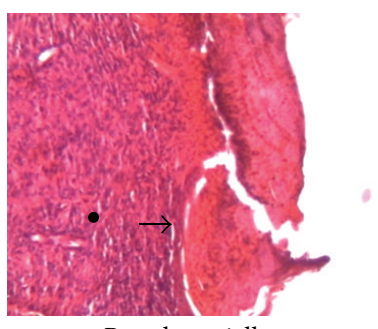

Petroleum jelly
FIGURE 2: Histopathologic observation of treated excisional wound with SSFAO 50\%, in natura avocado oil, EFA (control positive) or petroleum jelly (control negative) at the 14th day after operation. Skin sections show the hematoxylin and eosin stained epidermal (asterisk) and dermal (arrow) (40x magnification). Photographs are showing clear evidence for epithelization, keratinização and scar area formation in treated groups with SSFAO $50 \%$ or avocado oil. Data are shown as average \pm SEM $(n=06) .{ }^{*} P<0.05$ versus controls, ${ }^{* *} P<0.01$ versus controls, and ${ }^{* * *} P<0.001$ versus controls.

The group treated with $50 \%$ SSFAO or in natura avocado oil showed a significant increase $(P<0.05)$ in collagen density $(41.89 \pm 1.94 \%$ or $38.92 \pm 1.12 \%$ resp. $)$, when compared with the EFA control (31.04 $\pm 0.25 \%)$ or petroleum jelly control $(34.08 \pm 0.18 \%)$, respectively (Figures $4(\mathrm{a})$ and $4(\mathrm{~b})$ ). No difference was observed in the number of blood vessels among SSFAO 50\% or avocado oil groups when compared to controls.

3.4. Tensile Strength Analysis of Incisional Wounds. On the tenth day after operation, the tensile strength of the scar tissue was measured using EMIC tensiometer. A significant increase $(P<0.05)$ was observed in tensile strength in the SSFAO $50 \%$ or in natura avocado oil groups $\left(1.68 \pm 0.09 \mathrm{~g} / \mathrm{mm}^{2}\right.$ or $1.56 \pm 0.07 \mathrm{~g} / \mathrm{mm}^{2}$, resp.), when compared with the petroleum jelly control $\left(1.17 \pm 0.10 \mathrm{~g} / \mathrm{mm}^{2}\right)$ (Figure $\left.4(\mathrm{c})\right)$.

\section{Discussion}

Extracts of avocado ( $P$. americana Mill.) have been used in wound healing $[23,24]$. We note that the in natura avocado oil is rich in monounsaturated fatty acids, with oleic acid being the most prevalent, which corroborates with the results obtained by Tango et al. [31]. The linoleic and oleic acid contents are just shy of those described by Salgado et al. [33]; however, the amount of linolenic acids are above those verified by these authors. This fact can be caused by the anatomical region of the fruit, maturation stage, and geographic location of the growth of the plant $[44,45]$. 

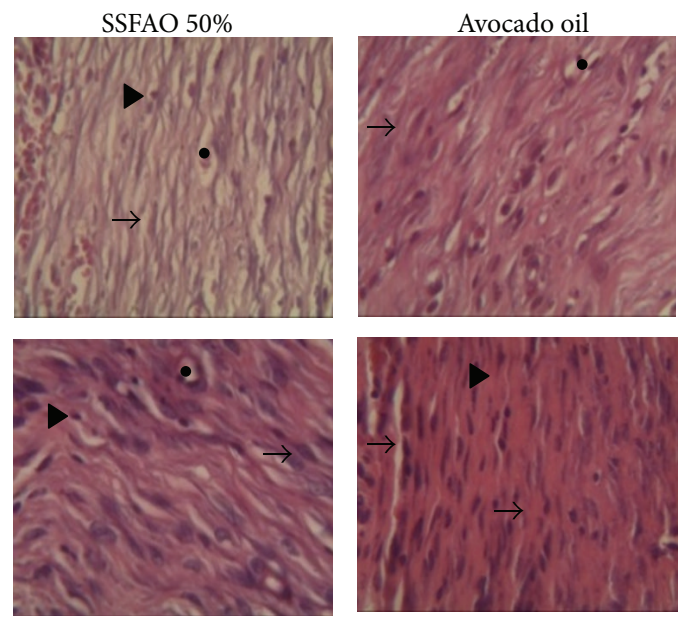

Petroleum jelly

(a)

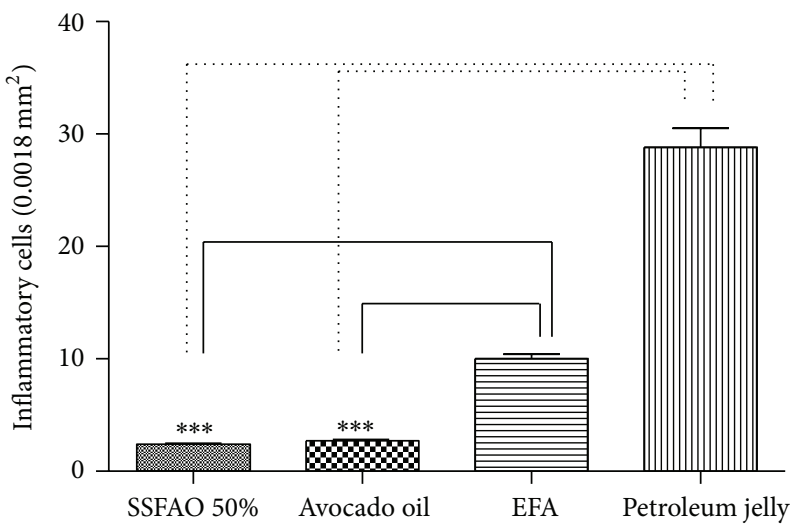

(b)

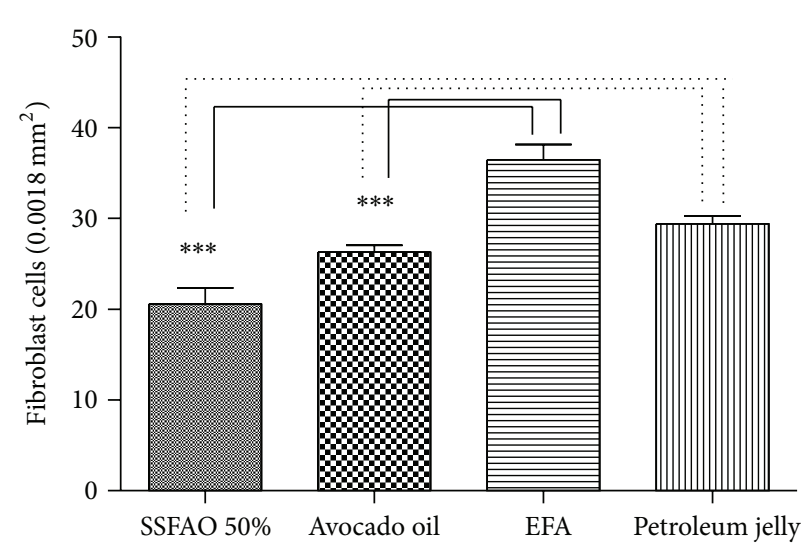

(c)

FIGURE 3: Histopathologic observation of treated excisinal wound with SSFAO 50\%, in natura avocado oil, EFA (control positive), or petroleum jelly (control negative) at the 14th day after operation. Tissue sections were stained with hematoxylin and eosin (400x magnification). (a) Representative images show granulation tissue presenting fibroblasts (arrow) and inflammatory cells (arrowheads) and surrounding capillaries (asterisk). Fewer inflammatory (b) and fibroblast (c) cells are seen in treated excisinal wound with SSFAO 50\% or in natura avocado oil when compared to controls. At least 30 different random fields were measured per treatment $(n=6)$. Data are shown as average \pm SEM. ${ }^{*} P<0.05$ versus controls; ${ }^{* *} P<0.01$.

Fatty acids (oleic, linoleic, and linolenic) have been the subject of several studies, because they seem to be active in the healing process $[10,38]$. The healing process can be monitored by assessing the rate of contraction of the wound, period of reepithelialization, tensile strength, and histopathology in different wound models [46]. We note that the rate of contraction of excisional wounds of animals treated with SSFAO $50 \%$ or avocado oil (fifth day) was slower than that present in the EFA control. A result similar to that was described by Franco et al. [38], who reported a significant delay in the contraction of the wounds, in the inflammatory stage of healing, in experimental groups compared to the EFA control. Probably, the delay in the contraction rate is related to the easy absorption of avocado oil through the skin $[26,27]$ allowing the wound bed to remain more exposed to the environment, increasing the chances of dehydration [38].
The best profile in the rate of contraction of wounds of animals treated with 50\% SSFAO or avocado oil (13th and 14th days) is probably related to the properties of the avocado oil (PUFA, MUFA, $\beta$-sitosterol, $\beta$-carotene, lecithin, minerals, and vitamins $\mathrm{A}, \mathrm{C}, \mathrm{D}$, and $\mathrm{E}$ ), which encouraged the migration, proliferation, and cell differentiation during the proliferative phase of wound healing. This finding corroborates those of Nayak et al. [23] and Vega et al. [24], which demonstrated the effectiveness of topical or oral administration of an extract from avocado fruit in different types of wounds using rats.

In this study, the presence of devitalized tissue (slough) was not verified in animals treated with SSFAO $50 \%$ or avocado oil, unlike animals treated with petroleum jelly. Hess and Kirsner [47] attributed the presence of devitalized tissue in the wound bed to tissue changes caused by oxygen, drying of the wound bed, or high microbial density. We 

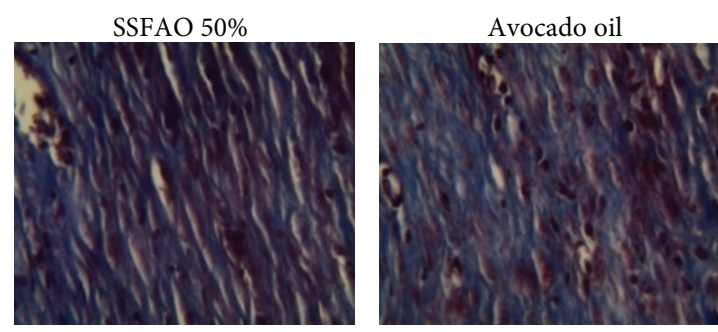

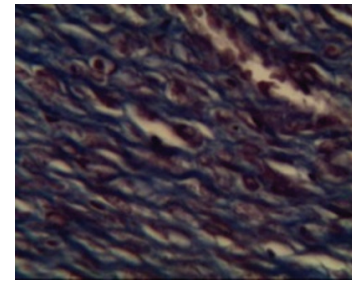

EFA

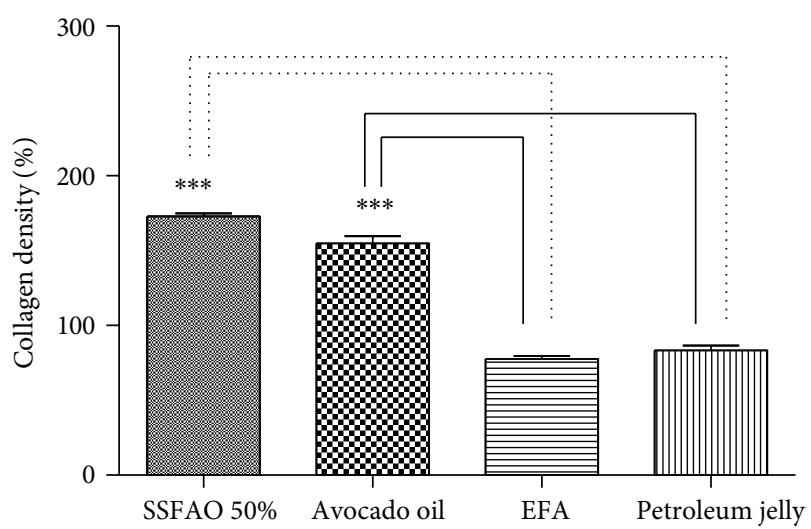

(b)

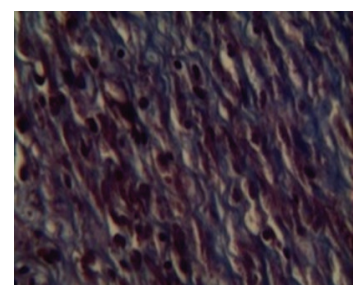

Petroleum jelly

(a)

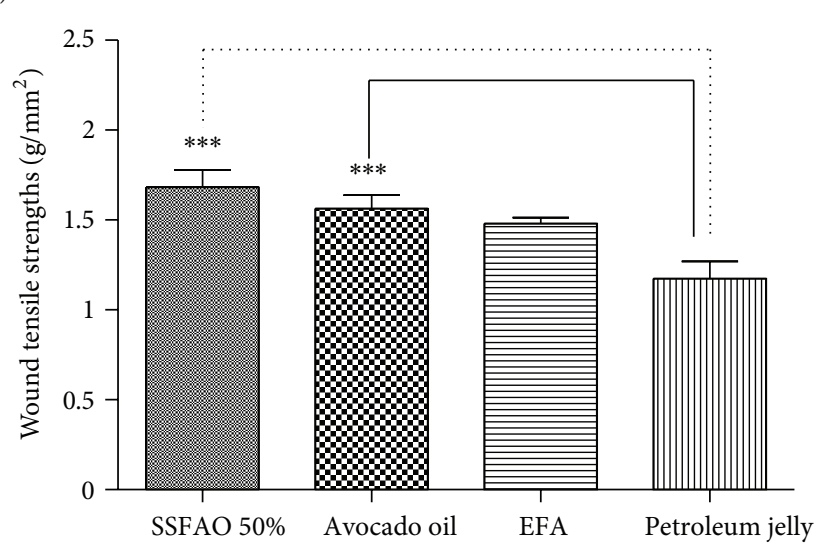

(c)

FIGURE 4: Histopathologic observation of treated wound with SSFAO 50\%, in natura avocado oil, EFA (control positive), or petroleum jelly (control negative). (a) Tissue sections stained with Masson's Trichrome (400x magnification) to collagen fibers. Greater collagen deposition (b) and tensile strength (c) are seen in treated wound with SSFAO $50 \%$ or in natura avocado oil when compared to petroleum jelly control. Data are shown as average \pm SEM. ${ }^{*} P<0.05$ versus controls, ${ }^{* *} P<0.01$ versus controls, and ${ }^{* * *} P<0.001$ versus controls.

suggest that the lack of development of slough in the groups treated with 50\% SSFAO or avocado oil is associated with the antimicrobial activity attributed to linoleic acid $[38,48]$, as well as the proper maintenance of hydration and oxygen stress in the wound bed.

The histopathological assessment revealed that the animals treated with 50\% SSFAO or avocado oil in natura showed a significant increase in the presence of epithelial tissue. The possible pharmacological effects attributed to avocado oil, in regard to the healing process, can be associated with its phytochemical compounds, such as vitamins (A and E) and fatty acids (oleic, linoleic, and linolenic acids). As these fatty acids are precursors of pharmacologically active substances, such as prostaglandins, thromboxanes, prostacyclins, and leukotrienes [15-20] that are involved in regulating cell division and differentiation, angiogenesis and synthesis of the extracellular matrix [22, 40, 49]. As does linoleic acid [50], vitamin $\mathrm{E}$ has important antioxidant functions [51] in combating free radicals that are responsible for the cytotoxicity and delay in tissue healing [52]. The adequate availability of these products provides a favorable environment to reepithelialization when administered to the wound bed.

Topical application of $50 \%$ SSFAO or avocado oil in natura promoted a reduction in the number of inflammatory cells in the scar tissue, characterizing anti-inflammatory activity. The modulation of the inflammatory response can be attributed to the high availability of oleic acid present in the SSFAO, since this fatty acid induces a less intense local inflammatory response, and competes with linoleic and linolenic acids for the same enzymes (cyclooxigenases and lipooxigenases) synthesizing less powerful inflammatory mediators than those formed by arachidonic acid $[15,18,19,21]$.

A significant decrease was observed in the number of fibroblast cells in animals treated with $50 \%$ SSFAO or in natura avocado oil; however, the collagen deposition was inversely proportional, characterizing the maturing of scar tissue (remodeling phase). 
There is a view that, in the physiological process of healing, collagen accumulates in the area of the wound until the 21st day after the injury; after this period, the balance between synthesis and degradation of collagen is restored [53], with a rapid disappearance (apoptosis) of fibroblastic cells [54].

A significant increase was observed in the tensile strength; this was proportional; the deposition of collagen, in animals treated with $50 \%$ SSFAO or in natura avocado oil. This finding is backed by Nunes et al. [55], Stoff et al. [56], Deodhar [57], and Udupa et al. [58], who reported that the resistance of the skin is related to formation, concentration, and chemical reorganization of the collagen fibers during the remodeling stage. According to Hunt [59], Stoff et al. [56], and López et al. [60], the tensile strength test is used to describe the quality of the healing from incisional wounds, this being one of the most reliable ways. Thus, the increase in tensile strength observed in this study may be due to increased collagen synthesis or due to a change in the maturation process, result of the action of mono- and polyunsaturated fatty acids present in avocado oil.

\section{Acknowledgments}

The authors would like to thank Belmira Lara da Silveira Andrade da Costa (Department of Physiology and Pharmacology), Clayton Anderson de Azevedo Filho (Department of Physiology and Pharmacology), and Sebastião Camilo de Melo Filho (Department of Nutrition) for help with the chromatographic analysis. They also thank Magno Felipe Holanda Barboza Inácio Teixeira (Department of Chemical Engineering), for her help in tensiometer analysis, and Silvania Tavares Paz (Department of Pathological) for histopathological techniques help.

\section{References}

[1] C. Templin, K. Grote, K. Schledzewski et al., "Ex vivo expanded haematopoietic progenitor cells improve dermal wound healing by paracrine mechanisms," Experimental Dermatology, vol. 18, no. 5, pp. 445-453, 2009.

[2] Y. Yamaguchi and K. Yoshikawa, "Cutaneous wound healing: an update," Journal of Dermatology, vol. 28, no. 10, pp. 521-534, 2001.

[3] J. D. Heilborn, G. Weber, A. Grönberg, C. Dieterich, and M. Ståhle, "Topical treatment with the vitamin D analogue calcipotriol enhances the upregulation of the antimicrobial protein hCAP18/LL-37 during wounding in human skin in vivo," Experimental Dermatology, vol. 19, no. 4, pp. 332-338, 2010.

[4] S. Werner and R. Grose, "Regulation of wound healing by growth factors and cytokines," Physiological Reviews, vol. 83, no. 3, pp. 835-870, 2003.

[5] K. Lau, R. Paus, S. Tiede, P. Day, and A. Bayat, "Exploring the role of stem cells in cutaneous wound healing," Experimental Dermatology, vol. 18, no. 11, pp. 921-933, 2009.

[6] P. Martin, "Wound healing-aiming for perfect skin regeneration," Science, vol. 276, no. 5309, pp. 75-81, 1997.

[7] S. R. Rahban and W. L. Garner, "Fibroproliferative scars," Clinics in Plastic Surgery, vol. 30, no. 1, pp. 77-89, 2003.
[8] J. C. McDaniel, M. Belury, K. Ahijevych, and W. Blakely, "Omega-3 fatty acids effect on wound healing," Wound Repair and Regeneration, vol. 16, no. 3, pp. 337-345, 2008.

[9] M. Novotný, T. Vasilenko, L. Varinská et al., "ER- $\alpha$ agonist induces conversion of fibroblasts into myofibroblasts, while ER? agonist increases ECM production and wound tensile strength of healing skin wounds in ovariectomised rats," Experimental Dermatology, vol. 20, no. 9, pp. 703-708, 2011.

[10] C. R. Cardoso, M. A. Souza, E. A. V. Ferro, S. Favoreto, and J. D. O. Pena, "Influence of topical administration of n-3 and n-6 essential and n-9 nonessential fatty acids on the healing of cutaneous wounds," Wound Repair and Regeneration, vol. 12, no. 2, pp. 235-243, 2004.

[11] L. U. Araújo, A. Grabe-Guimarães, V. C. F. Mosqueira, C. M. Carneiro, and N. M. Silva-Barcellos, "Profile of wound healing process induced by allantoinl," Acta Cirurgica Brasileira, vol. 25, no. 5, pp. 460-466, 2010.

[12] S. Schreml, M. Landthaler, M. Schaferling, and P. Babilas, "A new star on the $\mathrm{H}_{2} \mathrm{O}_{2}$ rizon of wound healing?" Experimental Dermatology, vol. 20, no. 3, pp. 229-231, 2011.

[13] U. Deiters, J. Barsig, B. Tawil, and P. F. Mühlradt, “The macrophage-activating lipopeptide-2 accelerates wound healing in diabetic mice," Experimental Dermatology, vol. 13, no. 12, pp. 731-739, 2004.

[14] F. Groeber, M. Holeiter, M. Hampel et al., "Skin tissue engineering-In vivo and vitro applications," Advanced Drug Delivery Reviews, vol. 128, no. 1, pp. 352-366, 2011.

[15] G. Cherian, "Metabolic and cardiovascular diseases in poultry: role of dietary lipids," Poultry Science, vol. 86, no. 5, pp. 10121016, 2007.

[16] J. M. Martins and N. D. Gruezo, "Ácidos graxos $\omega 6$ na etiologia do câncer de cólon e reto/ $\omega$-6 fatty acid and colorectal câncer," Revista Brasileira De Cancerologia, vol. 55, no. 1, pp. 69-74, 2009.

[17] I. Costea, D. R. Mack, D. Israel et al., "Genes involved in the metabolism of poly-unsaturated fatty-acids (PUFA) and risk for Crohn's disease in children \& young adults," PLoS ONE, vol. 5, no. 12, Article ID e15672, 2010.

[18] A. Garófolo and A. S. Petrilli, "Omega-3 and 6 fatty acids balance in inflammatory response in patients with cancer and cachexia," Revista de Nutricao, vol. 19, no. 5, pp. 611-621, 2006.

[19] P. M. M. Andrade and M. G. T. Carmo, "N-3 fatty acids: a link between eicosanoids, inflammation and immunity," $\mathrm{Nm}$ metabólica, vol. 08, no. 3, pp. 135-143, 2006.

[20] A. M. Astudillo, D. Balgoma, M. A. Balboa, and J. Balsinde, "Dynamics of arachidonic acid mobilization by inflammatory cells," Biochim Biophys Acta, vol. 1821, no. 2, pp. 249-256, 2012.

[21] P. C. Calder, "Polyunsaturated fatty acids and inflammation," Prostaglandins Leukotrienes and Essential Fatty Acids, vol. 75, no. 3, pp. 197-202, 2006.

[22] M. C. N. S. Carmo and M. I. T. D. Correia, "The role of omega-3 fatty acids in cancer," Revista Brasileira de Cancerologia, vol. 55, no. 3, pp. 279-287, 2009.

[23] B. S. Nayak, S. S. Raju, and A. V. Chalapathi Rao, "Wound healing activity of Persea americana (avocado) fruit: a preclinical study on rats," Journal of Wound Care, vol. 17, no. 3, pp. 123-126, 2008.

[24] R. M. G. Vega, R. R. Rivero, and R. G. Moreiro, "Study of avocado action on the process healing in burnt rats," Archivo Médico Camaguey, vol. 4, no. 2, pp. 39-43, 2000.

[25] M. Stücker, U. Memmel, M. Hoffmann, J. Hartung, and P. Altmeyer, "Vitamin B12 cream containing avocado oil in the 
therapy of plaque psoriasis," Dermatology, vol. 203, no. 2, pp. 141-147, 2001.

[26] J. S. Tango and J. M. Turatti, "Óleo de abacate," in Abacate: Cultura, Matéria-Prima, Processamento e Aspectos Econômicos, vol. 1, pp. 156-192, ITAL, Campinas, Brazil, 1992.

[27] G. R. Crizel and C. R. B. Mendonça, "Abacate: variedades, produção e aspectos nutricionais. Conhecimento sem fronteiras," in XVII Congresso de Iniciação Científica X Encontro de Pós-Graduação-UFPEL, 2008.

[28] H. Kawagishi, Y. Fukumoto, M. Hatakeyama et al., "Liver injury suppressing compounds from avocado (Persea americana)," Journal of Agricultural and Food Chemistry, vol. 49, no. 5, pp. 2215-2221, 2001.

[29] A. R. Gaby, "Natural remedies for scleroderma," Alternative Medicine Review, vol. 11, no. 3, pp. 188-195, 2006.

[30] S. E. Soares, J. Mancini Filho, and R. C. Della Modesta, "Sensory detection limits of avocado oil in mixtures with olive oil," Revista Española de Ciencia y Tecnologia de Alimentos, vol. 32, no. 5, pp. 509-516, 1992.

[31] J. S. Tango, C. R. L. Carvalho, and N. B. Soares, "Physical and chemical characterization of avocado fruits aiming at its potencial for oil extration," Revista Brasileira de Fruticultura, vol. 26, no. 1, pp. 17-23, 2004.

[32] M. A. Ortiz, A. L. Dorantes, M. J. Gallndez, and S. E. Cárdenas, "Effect of a novel oil extraction method on avocado (Persea americana Mill) pulp microstructure," Plant Foods for Human Nutrition, vol. 59, no. 1, pp. 11-14, 2004.

[33] J. M. Salgado, F. Danieli, M. A. B. Regitano-D’Arce, A. Frias, and D. N. Mansi, "The avocado oil (Persea americana Mill) as a raw material for the food industry," Ciencia e Tecnologia de Alimentos, vol. 28, pp. 20-26, 2008.

[34] G. Massafera, T. M. B. Costa, and J. E. D. Oliveira, "Fatty acids of mesocarp and seed oils of avocados (Persea americana Mill.) from Ribeirão Preto, SP," Alimentos e Nutrição, vol. 21, no. 1, pp. 325-331, 2010.

[35] L. Hartman, "Rapid preparation of fatty acid methyl esters from lipids," Laboratory Practive, vol. 22, no. 7, pp. 475-476, 1973.

[36] J. M. Davidson, "Animal models for wound repair," Archives of Dermatological Research, vol. 290, no. 1, pp. S1-S11, 1998.

[37] R. D. Galiano, J. Michaels, M. Dobryansky, J. P. Levine, and G. C. Gurtner, "Quantitative and reproducible murine model of excisional wound healing," Wound Repair and Regeneration, vol. 12, no. 4, pp. 485-492, 2004.

[38] E. S. Franco, C. M. F. Aquino, P. L. Medeiros et al., "Effect of a semisolid formulation of Linum usitatissimum L., (Linseed) oil on the repair of skin wounds," Evidence-Based Complementary and Alternative Medicine, vol. 2012, Article ID 270752, p. 7, 2012.

[39] S. F. Andrade, Manual de Terapêutica Veterinária, Roca, São Paulo, Brazil, 2002.

[40] Z. Zhang, S. Wang, Y. Diao, J. Zhang, and D. Lv, "Fatty acid extracts from Lucilia sericata larvae promote murine cutaneous wound healing by angiogenic activity," Lipids in Health and Disease, vol. 9, p. 24, 2010.

[41] L. G. Luna, Manual of Histologic Staining Methods of the Armed Forces Institute of Pathology, McGraw-Hill, New York, NY, USA, 3rd edition, 1968.

[42] P. Li, P. Liu, R. P. Xiong et al., "Ski, a modulator of wound healing and scar formation in the rat skin and rabbit ear," Journal of Pathology, vol. 223, no. 5, pp. 659-671, 2011.

[43] J. Michalany, Técnica Histológica Em Anatomia Patológica, Editora Pedagogica e Universitaria, São Paulo, Brasil, 1st edition, 1980.
[44] J. S. Tango, S. I. Costa, A. J. Antunes, and I. B. Figueiredo, “Composition du fruit et de l'huile de différentes variétés d'avocats cultivés dans l'Etat de São Paulo," Fruits, vol. 27, no. 1, pp. 143$146,1972$.

[45] E. M. Ahmed and C. R. Barmore, "Avocado," in Fruits of Tropical and sub Tropical Origin: Composition, Properties and Uses, S. Nagy, P. E. Shaw, and W. F. Wardowski, Eds., vol. 1, pp. 121-156, AVI Publishing, Lake Alfred, Fla, USA, 1990.

[46] N. Gupta and U. K. Jain, "Prominent wound healing properties of indigenous medicines," Journal of Natural Pharmaceuticals, vol. 1, no. 1, pp. 2-13, 2010.

[47] C. T. Hess and R. S. Kirsner, "Orchestrating wound healing: assessing and preparing the wound bed," Advances in Skin \& Wound Care, vol. 16, no. 5, pp. 246-258, 2003.

[48] V. Declair, "Treatmento of chronics ulcers of difficult cicatrization with linoleic acid," Jornal Brasileiro de Medicina, vol. 82, no. 6, pp. 36-41, 2002.

[49] P. M. Elias and B. E. Brown, "The mammalian cutaneous permeability barrier. Defective barrier function in essential fatty acid deficiency correlates with abnormal intercellular lipid deposition," Laboratory Investigation, vol. 39, no. 6, pp. 574-583, 1978.

[50] N. Y. Park, G. Valacchi, and Y. Lim, "Effect of dietary conjugated linoleic acid supplementation on early inflammatory responses during cutaneous wound healing," Mediators of Inflammation, vol. 2010, Article ID 342328, 8 pages, 2010.

[51] M. Musalmah, M. Y. Nizrana, A. H. Fairuz et al., "Comparative effects of palm vitamin $\mathrm{E}$ and $\alpha$-tocopherol on healing and wound tissue antioxidant enzyme levels in diabetic rats," Lipids, vol. 40, no. 6, pp. 575-580, 2005.

[52] S. Shetty, S. Udupa, and L. Udupa, "Evaluation of antioxidant and wound healing effects of alcoholic and aqueous extract of Ocimum sanctum Linn in rats," Evidence-based Complementary and Alternative Medicine, vol. 5, no. 1, pp. 95-101, 2008.

[53] J. A. Mack, S. R. Abramson, Y. Ben et al., "Hoxb13 knockout adult skin exhibits high levels of hyaluronan and enhanced wound healing," The FASEB Journal, vol. 17, no. 10, pp. 13521354, 2003.

[54] C. A. Balbino, L. M. Pereira, and R. Curi, "Mechanisms involved in wound healing: a revision," Brazilian Journal of Pharmaceutical Sciences, vol. 41, no. 1, pp. 27-51, 2005.

[55] J. A. T. Nunes, J. M. Ribas-Filho, O. Malafaia et al., "Evaluation of the hydro-alcoholic Schinus terebinthifolius raddi (Aroeira) extract in the healing process of the alba linea in rats," Acta Cirurgica Brasileira, vol. 21, no. 3, pp. 8-15, 2006.

[56] A. Stoff, A. A. Rivera, N. S. Banerjee et al., "Promotion of incisional wound repair by human mesenchymal stem cell transplantation," Experimental Dermatology, vol. 18, no. 4, pp. 362369, 2009.

[57] A. K. Deodhar, "Surgical physiology of wound healing: a review," Journal of Postgraduate Medicine, vol. 43, no. 2, pp. 5256, 1997.

[58] S. L. Udupa, A. L. Udupa, and D. R. Kulkarni, "Studies on the anti-inflammatory and wound healing properties of Moringa oleifera and Aegle marmelos," Fitoterapia, vol. 65, no. 2, pp. 119123, 1994.

[59] T. K. Hunt, "Basic principles of wound healing," Journal of Trauma, vol. 30, no. 12, pp. 122-128, 1990.

[60] H. S. López, L. O. Camberos, and A. A. Ocampo, "Evaluación comparativa de la mezcla propoleo zabila con cicatrizantes comerciales," Veterinaria Mexico, vol. 20, no. 1, pp. 407-413, 1989. 


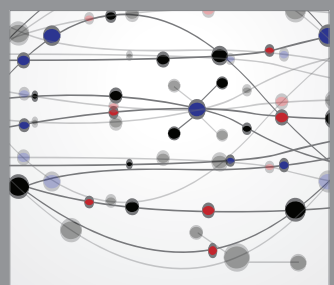

The Scientific World Journal
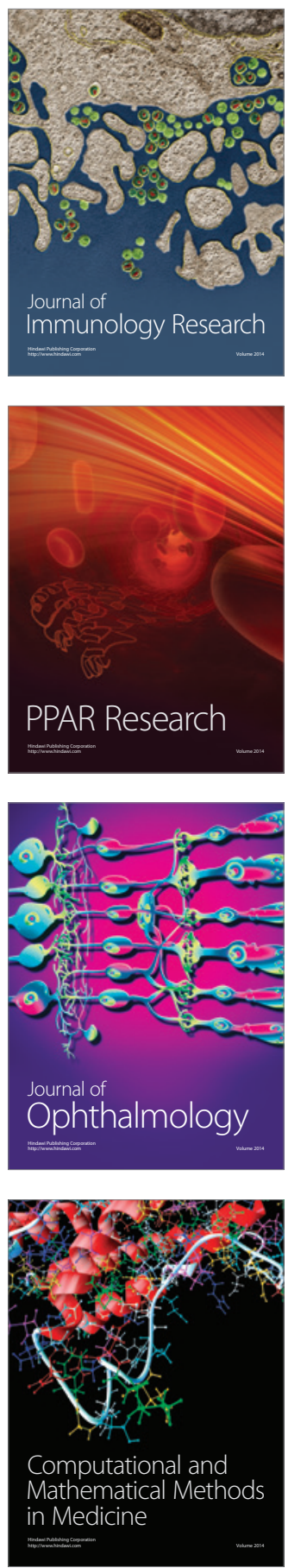

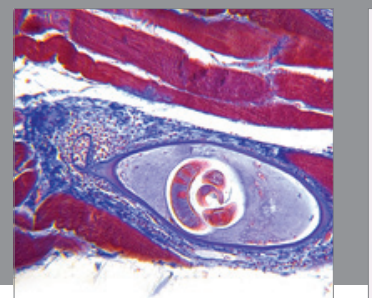

Gastroenterology

Research and Practice
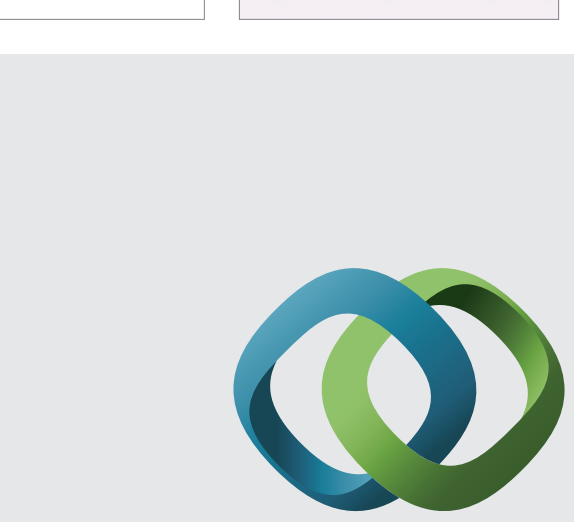

\section{Hindawi}

Submit your manuscripts at

http://www.hindawi.com
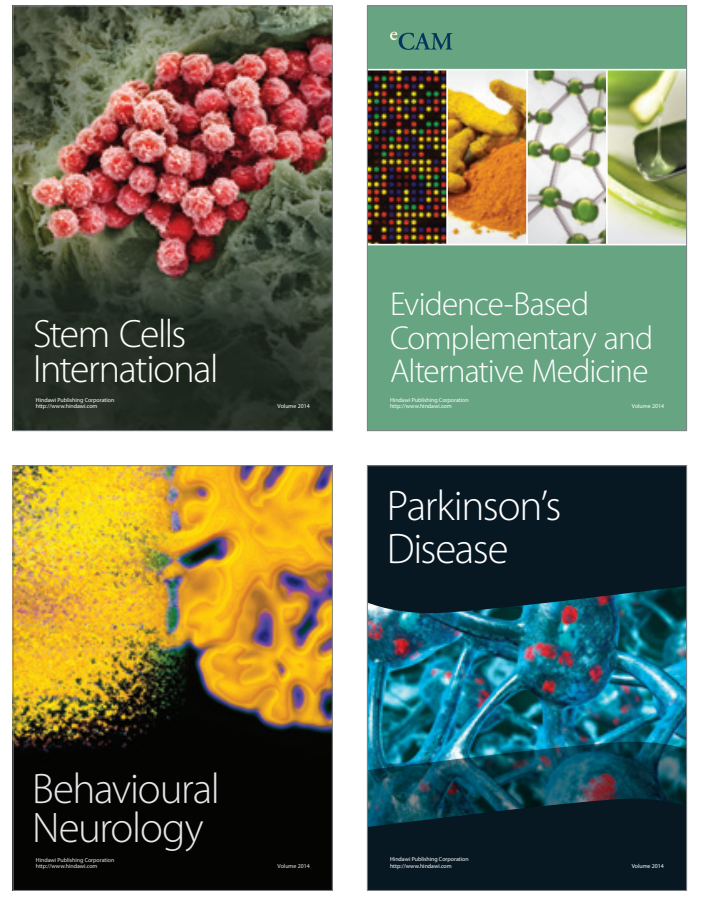
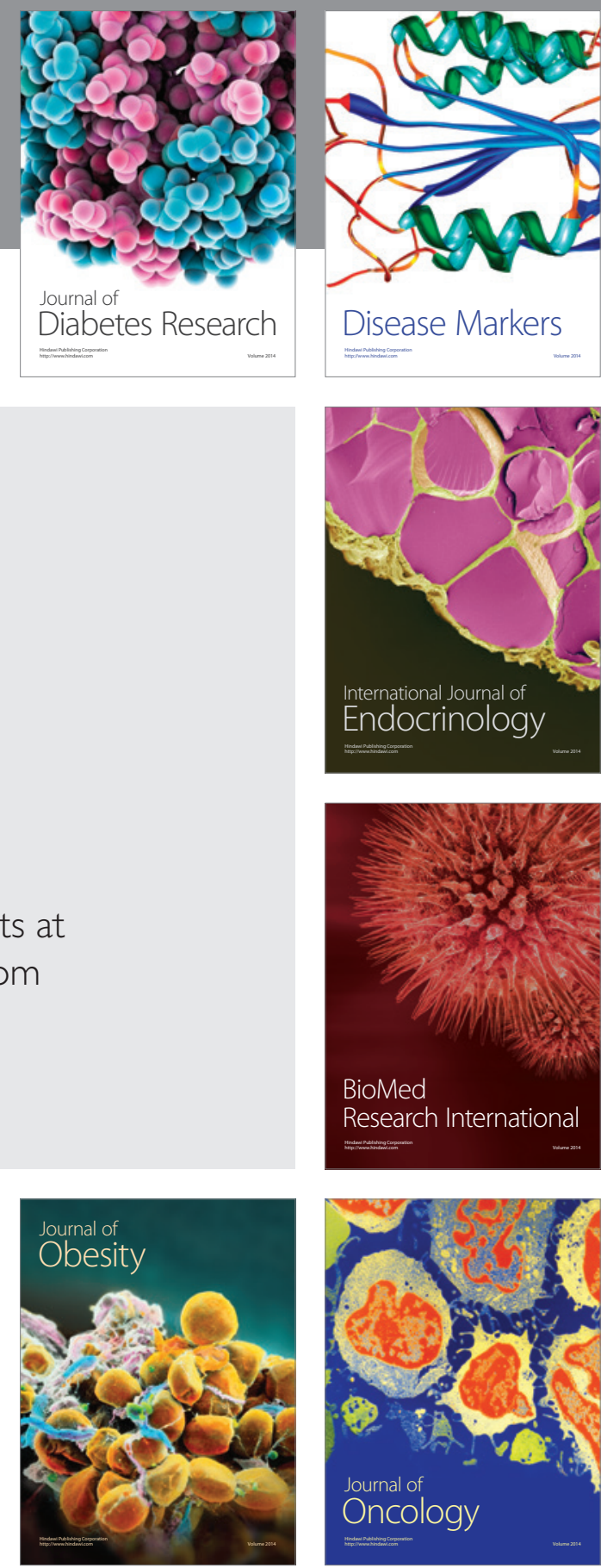

Disease Markers
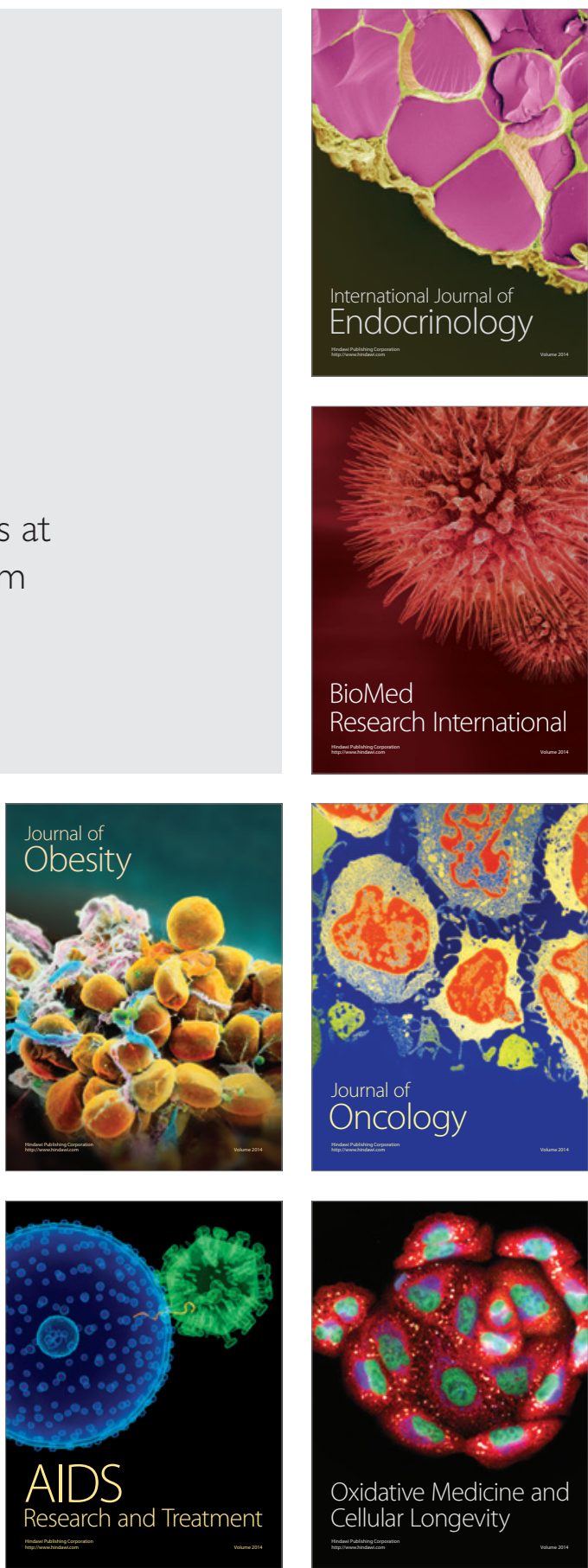